\title{
DAMPAK GELOMBANG EKUATORIAL ROSSBY TERHADAP PRODUKTIVITAS PERAIRAN, BARAT PASIFIK WARM POOL
}

\author{
IMPACT OF EQUATORIAL ROSSBY WAVE TO OCEAN PRIMARY PRODUCTIVITY, \\ IN THE WESTERN PACIFIC WARM POOL
}

\author{
Harold J. D. Waas ${ }^{1 *}$, Vincentius P. Siregar ${ }^{2 \S}$, Indra Jaya², Jonson Lumban Gaol ${ }^{2}$ \\ ${ }^{1}$ Program Studi Ilmu Kelautan, Fakultas Perikanan dan Ilmu Kelautan,Universitas Pattimura, Ambon \\ ${ }^{2}$ Departemen Ilmu Kelautan dan Teknologi, Fakultas Perikanan dan Ilmu Kelautan, \\ Institut Pertanian Bogor, Bogor \\ *E-mail: haroldjoppiewaas@gmail.com; §E-mail: vingar56@yahoo.com
}

Diterima tanggal: 11 juli 2014, diterima setelah perbaikan: 15 November 2014, disetujui tanggal: 28 november 2015

\begin{abstract}
ABSTRAK
Gelombang ekuatorial Rossby selama ENSO berperan penting di perairan oligotropik Barat Pasifik Warm Pool (BPWP) melalui efek rototiller gelombang Rossby. Dampak utamanya adalah blooming fitoplankton pada puncak gelombang dan pengangkatan kedalaman klorofil-a maksimum mendekati (di atas) dasar lapisan pencampuran. Kontribusi gelombang Rossby dalam meningkatkan produktivitas primer permukaan perairan berdasarkan hasil perhitungan data klimatologi dan data set bulanan ocean color berkisar antara $4-38 \%$ karena konsentrasi fitoplankton yang tinggi berada di bawah kedalaman lapisan pencampuran dan zona kedalaman optikal SeaWIFS. Walaupun kontribusi gelombang Rossby rendah tetapi secara signifikan berkontribusi terhadap tingginya hasil tangkapan tuna selama akhir episode ENSO (Januari - Maret). Aspek lain gangguan gelombang adalah peningkatan kelimpahan group fitoplankton Cyanobacteria dan Coccolitophores (komponen dari microbial loop) dasar dari rantai makan tuna dan mendominasi sebagian besar produksi primer pada puncak gelombang dan kedalaman klorofil-a maksimum.
\end{abstract}

Kata kunci: gelombang ekuatorial Rossby, ENSO, efek rototiller, kedalaman lapisan pencampuran, zona kedalaman optikal SeaWIFS

\section{ABSTRACT}

Equatorial Rossby waves during ENSO plays an important role in Western Pacific Warm Pool (WPWP) oligotrophic waters through rototiller rossby wave effect. The main impact of the wave is phytoplankton blooming on wave crest and the lifting of the deep chlorophyll-a maximum near (on basis) of mixed layer depth. Wave contribution to increasing of surface marine primary productivity based on calculations of climatology and monthly data set of ocean color ranged between $4-38 \%$ due to the high concentration of phytoplankton below of mixed layer depth and SeaWIFS optical depth zone. Although the contribution of rossby waves is low but significantly contributes to the high catches of tuna during the end of the ENSO episodes (January to March). Another aspect of the wave disturbances is the increasing abundance of Cyanobacteria and Coccolitophores phytoplankton groups (members of microbial loop) base of tuna food chain and dominates most of primary production and grazing at the wave crest and the deep chlorophyll-a maximum.

Keywords: equatorial Rossby wave, ENSO, rototiller effect, mixed layer depth, SeaWIFS optical depth zone

\section{PENDAHULUAN}

Perairan Barat Pasifik Warm Pool (BPWP) merupakan perairan oligotropik yang dicirikan oleh suhu permukaan laut (SPL) yang tinggi $\left(>29^{\circ} \mathrm{C}\right)$ dari rerata suhu perairan dunia, produktivitas primer dan klorofil-a yang rendah serta jenuh nitrat karena dibatasi oleh lapisan penghalang bersalinitas tinggi yang mengisolasi lapisan tercampur dengan pinoklin yang kaya nutrien (Ganachaud et al., 2011). Peningkatan kesuburan perairan hanya terjadi jika ada suplai 
nutrien baru dari pinoklin ke lapisan tercampur di zona eufotik (Mann dan Lazier, 2006).

Produktivitas perairan yang rendah berlawanan dengan kemampuan perairan dalam mendukung dan mempertahankan keberlangsungan perikanan tuna seperti Cakalang (Katsuwonus pelamis), Madidihang (Thunnus albacares), Tuna Mata besar (Thunnus obesus), dan Albacore (Thunnus alalunga). Diestimasi bahwa perairan Warm Pool mampu menyuplai hasil tangkapan tuna lebih dari 2,5 juta ton/tahun dan menyumbang sekitar $40 \%$ tangkapan tahunan tuna dunia. Dengan perkembangan armada penangkapan Purse seine Filipina dan Indonesia kawasan perairan BPWP mampu memberikan kontribusi sebesar 20-25\% dari total hasil tangkapan tuna di perairan barat dan sentral Pasifik (Lehodey et al.,2011).

Kemampuan ini tidak terlepas dari keadaan biogeokimia perairan yang menopang kehadiran makanan tuna dan sekaligus mempertahankan status perairan sebagai salah satu daerah penangkapan potensial tuna selain perairan timur Pasifik, perairan sekitar Jepang, dan pantai barat Afrika (Block dan Evans, 2001). Beberapa upaya telah dilakukan untuk mencari faktor penyebab lain yang meningkatkan kesuburan perairan oligotropik meliputi Eddies (McGillicuddy et al., 1998), migrasi diatom mats (Villareal et al., 1999), siklon tropis (Lin et al., 2003) dan gelombang planetary. Studi tentang gelombang ekuatorial init elah dilakukan oleh Mysak et al. (1982) di timur laut Pasifik, Pan et al. (2011) di Laut Cina Selatan, Cipollini et al. (2001); Kawamiya dan Oschdlies (2001); White et al. (2004) di Samudera Hindia, Charria et al. (2008) di Atlantik Utara dan Sakamoto et al. (2004) di utara Pasifik Tropis Gyre.

Studi gelombang Rossby di perairan Pasifik secara rinci telah dipublikasikan oleh Chelton et al. (2003) tetapi difokuskan pada aspek fisik gelombang sedangkan pengaruh gelombang internal tesebut terhadap aspek biogeokimia perairan yang berkaitan dengan peningkatan produktivitas primer perairan dan kehadiran tuna sangat terbatas. Sehubungan dengan perairan BPWP sebagai sumber utama ENSO (El Nino Southern Oscillation) dan responsif dengan gelombang Rossby maka dihipotesiskan bahwa gelombang tersebut merupakan salah satu mekanisme utama yang berperan dalam menyuburkan perairan BPWP dalam skala yang luas sehingga perairan mampu mempertahankan eksistensinya sebagai daerah penangkapan utama tuna selama berlangsungnya ENSO.

Tulisan ini bertujuan untuk menguraikan dan memahami: (1) mekanisme pengayaan kesuburan perairan oseanik dan kuantifikasi kontribusi gelombang Rossby terhadap peningkatan produktivitas primer permukaan perairan, (2) respons biogekimia perairan sebagai dampak gangguan gelombang Rossby, dan (3) dampak gangguan gelombang Rossby terhadap kelimpahan dan laju penangkapan (catch per unit effort) dari tiga spesies tuna yaitu Cakalang (Katsuwonus pelamis), Madidihang (Thunnus albacares) dan Tuna Mata Besar (Thunnus obesus) di perairan BPWP.

\section{BAHAN DAN METODE}

Studi ini bersifat eksploratif dengan menggabungkan metode penginderaan jauh satelit, Triton Buoy Mooring (TBM), Nasa Ocean Biogeochemical Model (NOBM) dan eksplorasi penangkapan tuna. Analisis difokuskan pada zonal $5{ }^{0} \mathrm{~N}$ mengacu pada Tomczak dan Godfrey (2001) dan Chelton et al. (2003) bahwa zonal $5-8{ }^{0} \mathrm{~N}$ merupakan wilayah perairan yang intensif dipengaruhi oleh gelombang Rossby selama ENSO (Gambar 1).

Data yang digunakan meliputi: (1) data set klimatologi bulanan, distribusi vertikal nitrat dan suhu perairan, kedalaman lapisan tercampur (Mixed Layer Depth/MLD), batas atas kedalaman termoklin, Ocean color SeaWIFS, dan SPL NOAA/AVHRR, (2) data set citra komposit bulanan tahun 1997/1998 meliputi anomali tinggi paras laut (Sea Surface Height Anomaly/SSHA), deviasi tinggi paras laut (Sea Surface Height deviation/SSHD), ocean color SeaWIFS, SPL, total klorofil, nitrat, besi terlarut $\left(\mathrm{Fe}_{\mathrm{D}}\right)$, dan empat kelompok utama fitoplankton yaitu Cyanobacteria, Coccolithophores, Diatom dan Chlorophytes (tahun 1998), (3) data rekaman TBM meliputi anomali suhu air, ketinggian dinamik dan isoterm $20{ }^{\circ} \mathrm{C}$ yang bersesuaian waktunya dengan rekaman data satelit, dan (4) data hasil tangkapan tuna armada Purse seine Jepang tahun 1998 pada wilayah perairan sekitar transek dan BPWP tahun 
yang sama. Data dikoleksi melalui NOAA PMEL LAS, APDRC LAS, Giovanni LAS, Tropical Atmospheric Ocean Project LAS dan Western \& Central Pacific Fisheries Commision (WCPFC).

Pencuplikan data gelombang Rossby dilakukan dengan membuat transek horisontal (cross section) pada zonal $5{ }^{\circ} \mathrm{N}$ sepanjang bujur $125-180{ }^{\circ} \mathrm{E}$ menggunakan data klimatologi bulanan, sedangkan pencuplikan data selama ENSO dilakukan dengan membuat transek pada zonal $5^{\circ} \mathrm{N}$ bujur $135-165^{\circ} \mathrm{E}$ menggunakan data komposit bulanan citra satelit dan TBM. Analisis data dilakukan dengan membuat sebaran vertikal nitrat dan suhu perairan mengacu pada Radenac dan Rodier (1996) dan Krauss (1967) dikompilasikan dengan kedalaman MLD, batas atas termoklin, rerata kedalaman klorofil-a maksimum (Deep Chlorophyll-a Maximum/DCM) di BPWP ( 100 m ; Mackey et al.2002) dan zona kedalaman optikal SeaWIFS (Sakamoto et al. 2004). Analisis dilakukan menggunakan APDRC LAS 8 kecuali kedalaman klorofil-a maksimum dan zona kedalaman optikal SeaWIFS. Analisis adveksi vertikal nitrat menggunakan isoplet nitrat $1,0 \mu \mathrm{M} / \mathrm{l}$ yang umumnya digunakan untuk menentukan ambang batas nitraklin yang berasosiasi dengan DCM.

Analisis kuantifikasi besarnya sumbangan gelombang Rossby terhadap peningkatan produktivitas primer permukaan perairan dihitung berdasarkan nilai persentase varians (\%) klorofil-a permukaan perairan yang dihitung berdasarkan nilai integrasi kedalaman klorofil-a pada zona kedalaman optikal SeaWIFS mengacu pada Charria et al. (2008) dengan bentuk persamaan:

$\mathrm{s}^{2}=\frac{\sum_{\mathrm{y}^{2}}-\frac{(\Sigma \mathrm{y})^{2}}{\mathrm{n}}}{\mathrm{n}-1}$

dimana, :

$\mathrm{s}^{2}=$ nilai varians klorofil-a

$\mathrm{n}=$ jumlah data

$\mathrm{y}=$ klorofil-a $\left(\mathrm{mg} / \mathrm{m}^{3}\right)$

$\mathrm{s}^{2}(\%)=\frac{\mathrm{s}^{2}}{\sum \mathrm{s}^{2}} * 100 \%$

Analisis respons biogeokimia perairan menggunakan nitrat, $\mathrm{Fe}_{\mathrm{D}}$, total klorofil dan empat grup utama fitoplankton hasil asimilasi NOBM yang diekspresikan dalam bentuk diagram Hovmuller plots menggunakan Giovanni LAS. Model sangat komperhensif dan interaktif dan dikompilasikan dengan sirkulasi dan radiatif model untuk perairan global juga telah divalidasi secara ekstensif bersama-sama dengan data set in situ dan atau data set satelit (Gregg dan Cassey, 2007). Analisis kelimpahan dan laju tangkapan (CPUE) tuna dalam interaksinya dengan gangguan gelombang Rossby menggunakan data hasil tangkapan dua armada Purse seine Jepang tahun 1998 yang peroleh melalui WCPFC. Analisis kelimpahan dilakukan berdasarkan jumlah total hasil tangkapan setiap spesies tuna per bulannya (ton) dan laju tangkapan mengacu pada Pre Sparre dan Venema (1999) dengan bentuk persamaan :

CPUE $=\frac{\text { Catch }(\text { ton })}{\text { Effort }(\text { hari })}$

dimana, :

Catch $=$ total hasil tangkapan spesies tuna (ton)

Effort $=$ total hari operasi penangkapan (hari)

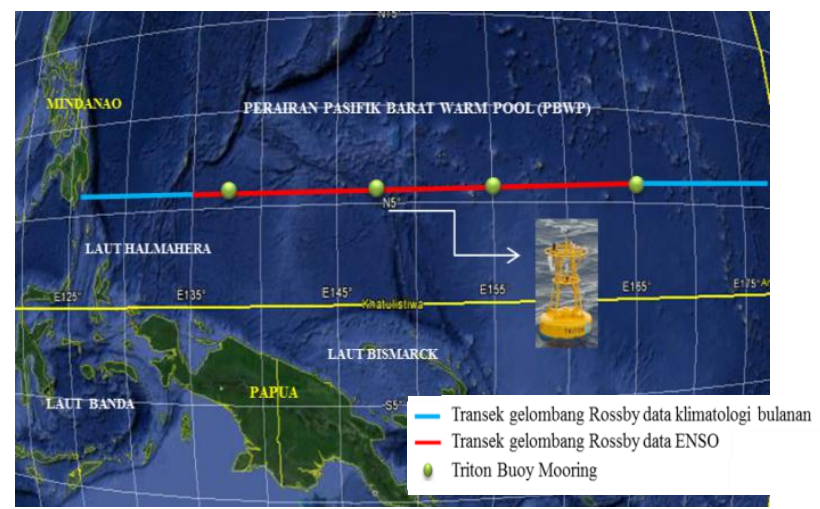

Gambar 1. Peta lokasi penelitian

Figure 1. Research location map

Sumber: Google Earth

\section{HASIL DAN PEMBAHASAN}

\subsection{Gelombang Ekuatorial Rossby}

Gelombang ekuatorial Rossby dikenal sebagai gelombang Rossby, gelombang baroklinik, gelombang internal, dan gelombang planetary dihasilkan sebagai respons terhadap anomali angin zonal permukaan yang disebabkan oleh kencangnya embusan angin barat (Westerly Wind Burst/WWBs) yang berasosiasi dengan Madden and Jullian Oscillation dengan kecepatan zonal angin $>4 \mathrm{~m} / \mathrm{s}$ berlangsung setidaknya $30-60$ hari sampai beberapa bulan (McPhaden, 1999). WWBs menyebabkan pergeseran Warm Pool yaitu kolam air hangat yang mengapung di atas air dingin bersalinitas tinggi ke timur merambat sebagai 
gelombang Kelvin. Kekosongan air yang ditinggalkan oleh massa air hangat tersebut digantikan melalui taikan air dingin dari lapisan yang lebih dalam dan merambat ke barat Pasifik. Taikan air ini kelihatan mulai berkembang selama Juli pada zonal $0^{\circ}, 2-10{ }^{\circ} \mathrm{N}$ dan 2-10 ${ }^{\circ} \mathrm{S}$ kecuali pada bulan Maret kelihatan pada zonal $8{ }^{\circ} \mathrm{N}$ di BPWP.

Selama perambatannya, pengaruh gaya Coriolis menyebabkan percabangan utara dan selatan pada zonal 5-10 ${ }^{\circ} \mathrm{N}$ dan 5-10 ${ }^{\circ} \mathrm{S}$ lebih luas dari hasil yang dijelaskan secara teoritis oleh Tomczack dan Godfrey (2001) maupun Chelton et al. (2003) (Gambar 2). Dari kedua kutub rambatan tersebut gelombang Rossby lebih terkonsentrasi pada kutub rambatan utara dengan intensitas yang menguat bersamaan dengan meningkatnya lintang. Di kutub rambatan selatan, walaupun terkonsentrasi pada wilayah zonal yang sama namun intensitasnya melemah dengan meningkatnya lintang. Perambatan gelombang juga diikuti oleh isoterm $20{ }^{\circ} \mathrm{C}$ dan ketinggian dinamik (Yu dan McPhaden, 1999).

Gelombang Rossby kutub rambatan utara mendominasi perairan BPWP selama periode musim barat akhir dari perkembangan ENSO untuk menciptakan taikan di timur perairan Filipina dan coastal upwelling di utara kontinen Papua. Gelombang Rossby kutub rambatan selatan mendominasi perairan Laut Solomon dan sekitarnya serta perairan kawasan timur Indonesia seperti Laut Aru, Arafura, Seram dan Banda untuk membangkitkan taikan di kawasan perairan tersebut selama periode musim timur.

Hasil identifikasi pada cross section $5{ }^{\circ} \mathrm{N}$ sepanjang bujur $135-165{ }^{\circ} \mathrm{E}$ memperlihatkan bahwa gelombang baroklinik tersebut identik dengan SSHA negatif dan ketinggian dinamik yang rendah akibat pengangkatan isoterm $20{ }^{\circ} \mathrm{C}$ lebih dangkal dan juga bersesuaian dengan pendangkalan anomali air dingin yang kelihatan pada cross section (Gambar 3). Propagasi gelombang kelihatan lebih smooth jika dibandingkan dengan pola perambatannya di lintang menengahyang membentuk pola diagonal pada longitude -time plot di zonal $28^{\circ} \mathrm{S}, 37,75^{\circ} \mathrm{S}$, $22,5^{\circ} \mathrm{N}$ dan $34^{\circ} \mathrm{N}$ sebagai akibat pengaruh gaya Coriolis dan perbedaan lintang yang signifikan (Cipollini et al., 2001).

\subsection{Mekanisme Pengayaan Perairan}

Efek biologis gelombang Rossby dihasilkan melalui adveksi vertikal massa air dingin kaya nutrien dari pinoklin (nitraklin) ke MLD terjadi di puncak gelombang selama musim barat (JanuarMaret) pada cross section gelombang. Hasil analisis menunjukkan bahwa rambatan gelombang Rossby selama Januari menghasilkan dua puncak gelombang yang berada disekitar bujur $125-140{ }^{\circ} \mathrm{E}$ dan 160-175 ${ }^{\circ}$ E. Puncak gelombang utama terpusat pada bujur $133{ }^{\circ} \mathrm{E}$ (SSHA $\left.(-8,5) \mathrm{cm}\right)$ sedangkan lembah gelombang berada pada wilayah perairan sekitar bujur $142-160{ }^{\circ} \mathrm{E}$ (SSHA $8 \mathrm{~cm}$ ) (Gambar 4a). Kedalaman adveksi isoplet nitrat $1,0 \mu \mathrm{m} / \mathrm{l}$ yang berasosiasi dengan suhu perairan $26-27{ }^{\circ} \mathrm{C}$ mendekati kedalaman $38 \mathrm{~m}$ diatas kedalaman rerata MLD (18-47m; rerata $34 \mathrm{~m})$ pada bagian puncak gelombang. Dengan membandingkan kedalaman adveksi nitrate, MLD dan zona kedalaman optikal SeaWIFS $(25-40 \quad \mathrm{~m})$ dapat dijelaskan bahwa blooming fitoplankton terjadi pada kedalaman $2 \mathrm{~m}$ di atas dasar MLD maksimum sehingga fluoresensi yang dihasilkan oleh fitoplankton terdeteksi pada sensor SeaWIFS sebagai konsentrasi klorofil-a yang lebih tinggi. Sementara itu, pada bagian lembah gelombang yang dicirikan oleh MLD yang lebih dalam (26-60 $\mathrm{m}$; rerata $47 \mathrm{~m}$ ) dan penenggelaman isoplet 1.0 $\mu \mathrm{m} / 1$ yang berasosiasi dengan suhu $26-27{ }^{\circ} \mathrm{C}$ di kedalaman 80-100 m. Blooming fitoplankton dapat terjadi di bawah MLD atau di dasar zona eufotik pada lembah gelombang dengan fluoresensi tidak menjangkau zona kedalaman optikal SeaWIFS.

Hasil analisis gelombang Rossby pada Februari (Gambar 3b) memperlihatkan bahwa gelombang internal ini membentuk tiga puncak gelombang sepanjang cross section dengan puncak utama terkonsentrasi pada bujur $133{ }^{\circ} \mathrm{E}$. Blooming fitoplankton terjadi pada bujur $125-140 \quad{ }^{\circ} \mathrm{E}$ diindikasikan oleh adveksi isopletnitrat 1,0 $\mu \mathrm{m} / \mathrm{l}$ $\left(26-27{ }^{\circ} \mathrm{C}\right)$ pada kedalaman $35 \mathrm{~m}$ di atas kedalamaman MLD (28-39 m; rerata $34 \mathrm{~m}$ ) atau pada kedalaman $4 \mathrm{~m}$ di atas dasar MLD maksimum. Sementara di bagian lembah gelombang pada bujur $140-147{ }^{\circ} \mathrm{E}$ (SSHA $9 \mathrm{~cm}$ ) ditandai oleh MLD yang lebih dalam (34-45 m; rerata $41 \mathrm{~m})$. Adveksi isoplet $1,0 \mu \mathrm{m} / 1\left(26-27{ }^{\circ} \mathrm{C}\right)$ mendekati kedalaman 80-105 m. Blooming fitoplankton terjadi di bagian bawah MLD atau dekat dasar zona eufotik namun tidak terjangkau oleh zona kedalaman optikal SeaWIFS. Perairan 


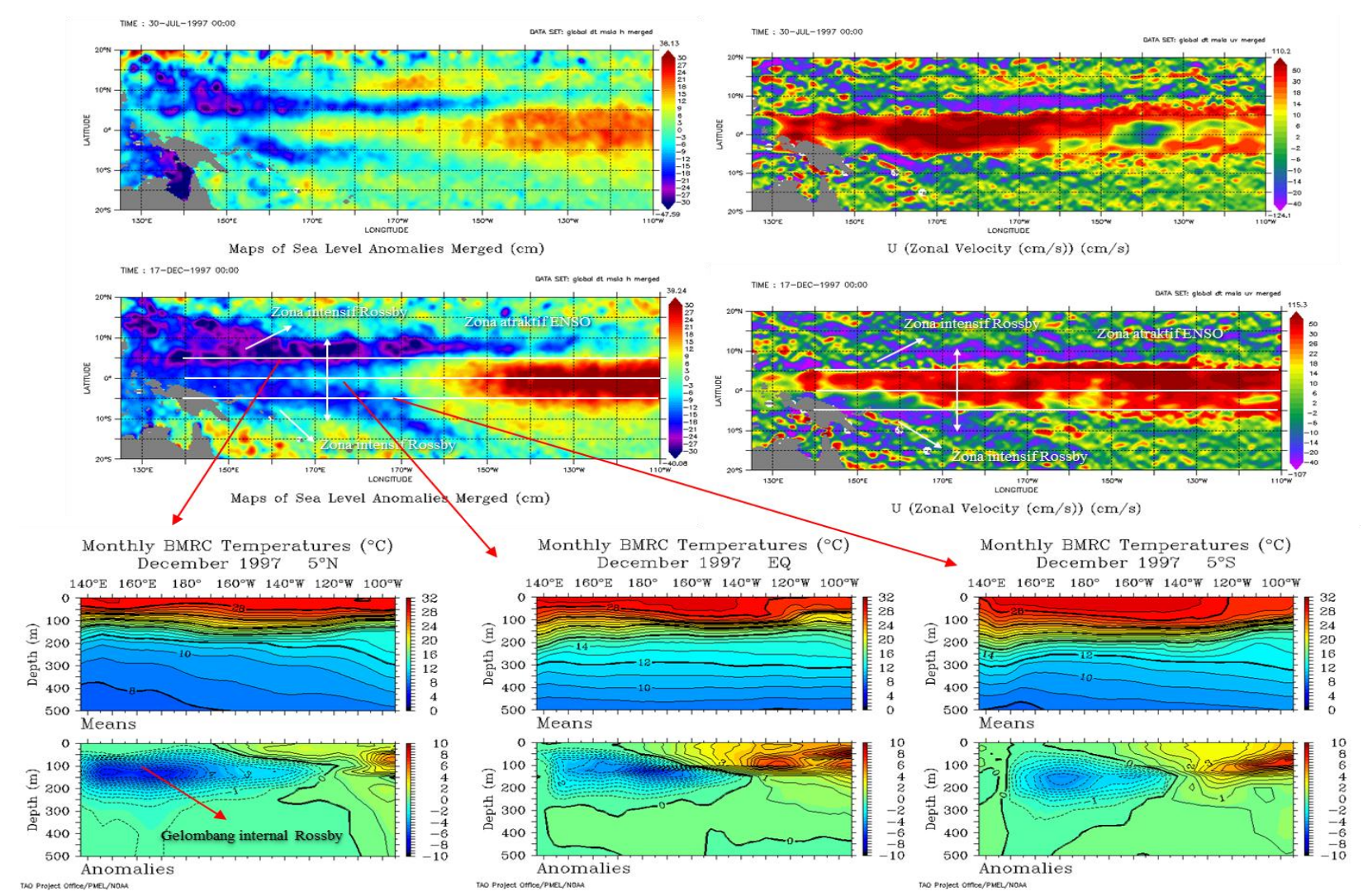

Gambar 2. Kenampakan gelombang Rossby (Juli \& Desember) ENSO 1997/1998

Figure 2. Appearance of Rossby waves (July \& December) ENSO 1997/1998

Sumber: Hasil analisis

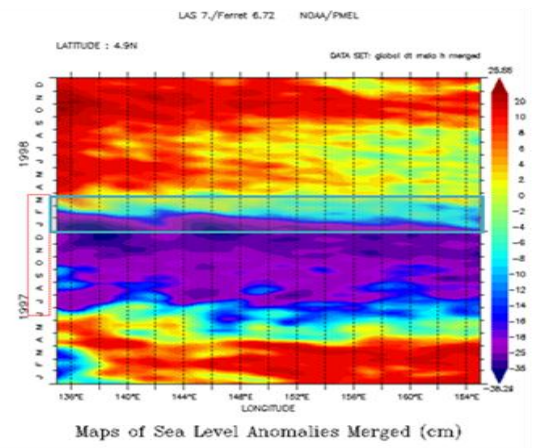

(a)

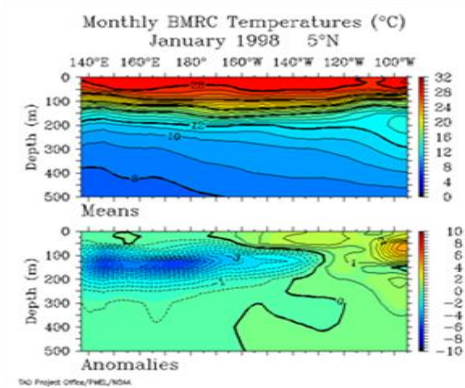

Gambar 3. Kunci identifikasi gelombang Rossby (Januari - Maret) 1998

Figure 3. Key indentification of rossby wave (January - March) 1998

Sumber: Hasil analisis 
dengan puncak gelombang yang terpusat pada bujur $152{ }^{\circ} \mathrm{E}$, adveksi nitrat lemah mencapai MLD dan berada di luar jangkauan zona kedalaman optikal SeaWIFS. Blooming fitoplankton juga terjadi pada bujur $175^{\circ} \mathrm{E}$ dimana adveksi vertikal isopletnitrat $1,0 \mu \mathrm{m} / \mathrm{l}$ dapat mencapai permukaan perairan sekitar bujur $170-180{ }^{\circ} \mathrm{E}$.

Rambatan gelombang Rossby pada Maret (Gambar 3c) membentuk tiga puncak gelombang dengan gelombang utama terkonsentrasi pada bujur 25-140 ${ }^{\circ} \mathrm{E}$ dengan puncak gelombang berada pada bujur $133{ }^{\circ} \mathrm{E}$. Adveksi nitrat mencapai MLD diindikasikan oleh isoplet $1,0 \quad \mu \mathrm{m} / 1 \quad\left(27 \quad{ }^{\circ} \mathrm{C}\right)$ mencapai kedalaman $35 \mathrm{~m}$ sementara MLD lebih dalam (23-58 $\mathrm{m}$; rerata $40 \mathrm{~m})$. Blooming fitoplankton terjadi dalam MLD dan fluoresensi yang kuat dihasilkan oleh fitoplankton dapat terekam pada sensor karena berada pada jangkauan zona kedalaman optikal SeaWIFS. Di bagian lembah gelombang, pada bujur antara $140-150{ }^{\circ} \mathrm{E}$ (SSHA 13,5 cm) walaupun MLD dalam (46- $60 \mathrm{~m}$; rerata $53 \mathrm{~m}$ ) namun adveksi vertikal isoplet nitrat $1,0 \mu \mathrm{m} / 1\left(26-27{ }^{\circ} \mathrm{C}\right)$ tidak menjangkau kedalaman MLD karena berada pada kedalaman 80-100 m. Blooming fitoplankton terjadi di bawah kedalaman MLD atau pada bagian perairan yang mendekati dasar zona eufotik namun tidak terjangkau oleh zona kedalaman optikal SeaWIFS. Keadaan yang sama juga diperlihatkan oleh gelombang dengan puncaknya pada bujur $155^{\circ} \mathrm{E}$ dimana adveksi vertikal isopletnitrat $1,0 \mu \mathrm{m} / 1\left(26-27{ }^{\circ} \mathrm{C}\right)$ hanya menjangkau kedalaman 80-105 m tidak mencapai kedalaman MLD maupun zona kedalaman optikal SeaWIFS. Sebaliknya, gelombang dengan puncaknya pada bujur $173^{\circ} \mathrm{E}$ (SSHA $5 \mathrm{~cm}$ ) menghasilkan blooming fitoplankton yang mengarah pada bujur $180^{\circ} \mathrm{E}$ karena adveksi isopletnitrat $1,0 \mu \mathrm{m} / \mathrm{l}$ mencapai permukaan perairan dan zona kedalaman optikal SeaWIFS.

Dari hasil analisis dapat dijelaskan bahwa peningkatan produktivitas primer permukaan perairan PBWP yang diakibatkan oleh gelombang Rossby terjadi pada bagian puncak gelombang utama di mana intensitas taikan kuat terjadi. Sebagai konsekwensinya, nutrien dengan konsentrasi yang tinggi dari nitraklin yang berasosiasi dengan DCM terangkat mencapai kedalaman dangkal di atas dasar MLD dan dijangkau oleh zona kedalaman optikal SeaWIFS.
Pengangkatan tersebut secara langsung berdampak terhadap peningkatan konsentrasi fitoplankton dan produktivitas primer di permukaan perairan namun proporsi terbesar konsentrasi klorofil-a yang tinggi berada di bawah kedua kedalaman tersebut. Sementara di lembah gelombang dan puncak gelombang dimana taikan lemah, blooming fitoplankton terjadi pada kedalaman 80-120 m yaitu kisaran kedalaman yang mendekati nitraklin dan DCM di barat Pasifik (60-150 m) (Mackey et $a l .$, 2002) namun fluoresensi yang dihasilkan oleh fitoplankton tidak mencapai zona kedalaman optikal satelit.

Mekanisme tingginya konsentrasi klorofil-a pada puncak gelombang dan rendah di bagian lembah gelombang merupakan efek rototiller gelombang Rossby yang menyebabkan adveksi air dingin yang kaya nutrien ke permukaan melalui taikan nitraklin di sisi terdepan densitas gelombang dan mendorong pertumbuhan fitoplankton. Air dengan nutrien yang rendah ditenggelamkan di sisi yang lain, sehingga respons terhadap proses linier taikan adalah non linier (Siegel, 2001). Mekanisme ini berbeda dengan Eddies yang menginduksi nutrien dari pusaran, cenderung mempertahankannya dalam inti pusaran dan hanya mengadveksiair vertikal ketika intensif atau lemah, sedangkan gelombang Rossby akan mengangkat nutrien dan menenggelamkan air yang kehilangan nutrien sepanjang jalur propagasinya (Killworth et al., 2007).

Hasil kajian ini dibuktikan melalui analisis diagram Hovmuller plotsdata satelit Ocean color, SSHA dan SPL. Gambar 5 memperlihatkan bahwa perairan di sekitar puncak gelombang utama (SSHA negatif) memiliki klorofil-a yang tinggi berkisar antara 0,06-0,18 $\mathrm{mg} / \mathrm{m}^{3}$ (rerata 0,11 $\mathrm{mg} / \mathrm{m}^{3}$ ). Sementara di sekitar lembah gelombang (SSHA positif) maupun gelombang lainnya dengan taikan nitrat lemah memiliki konsentrasi klorofil-a yang rendah antara $0,05-0,12 \mathrm{mg} / \mathrm{m}^{3}$ (rerata 0,08 $\mathrm{mg} / \mathrm{m}^{3}$ ). Di perairan sekitar sentral kolam hangat International Date Line $\left(165-180^{\circ} \mathrm{E}\right)$ konsentrasi klorofil-a memiliki nilai yang sama dengan puncak gelombang utama walaupun termoklin lebih dalam. Hal ini disebabkan oleh adveksi horisontal cold tangue atau jalur air dingin indikator equatorial upwelling dari sentral Pasifik yang menjangkau bujur $145^{\circ}$ E selama periode La Nina atau Eddies yang dihasilkan karena gelombang Rossby 

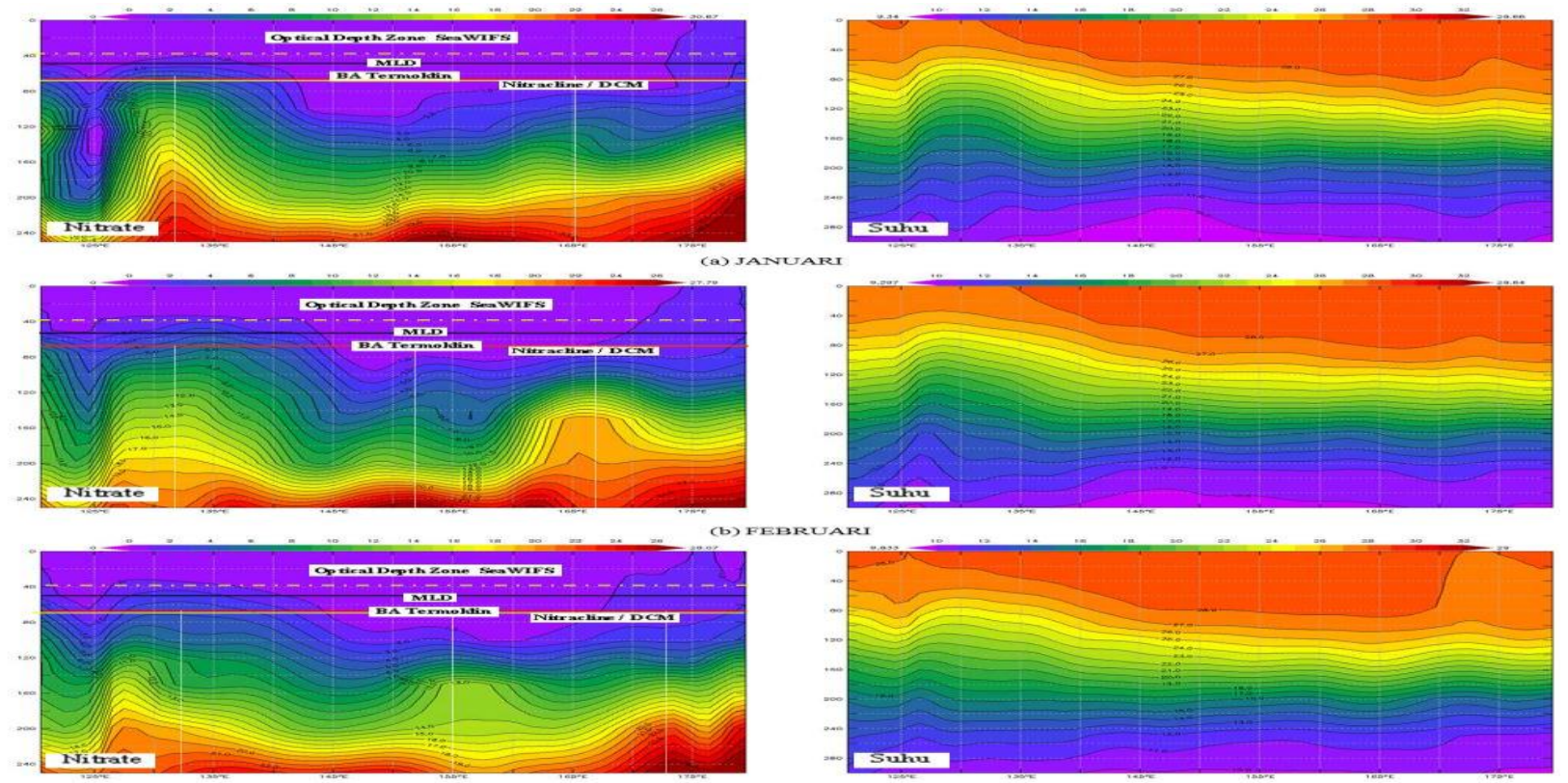

(c) MARET

Gambar 4. Distibusi vertical nitrat dan suhu perairan sebagai manifestasi gelombang Rossby (Januari-Maret) Figure 4. Vartical distribution of nitrate and water temperature as a manifestation of Rossby wave (JanuaryMarch)

Sumber: Hasil analisis

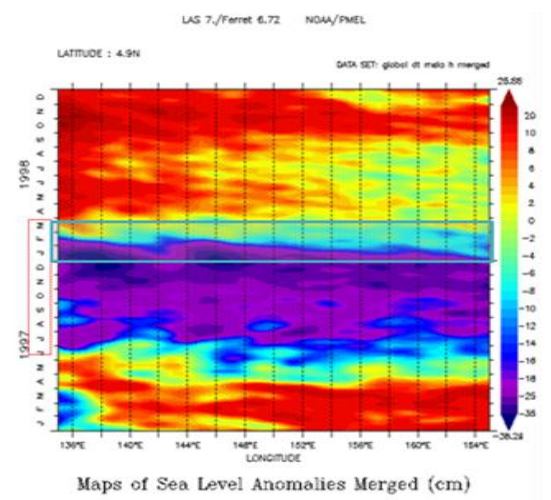

(a)

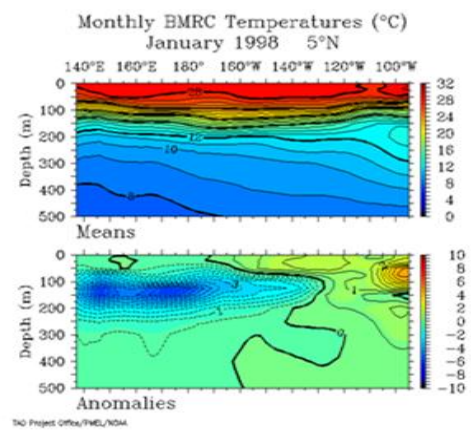

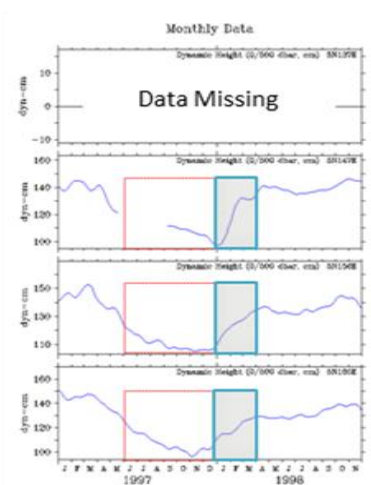

(b)

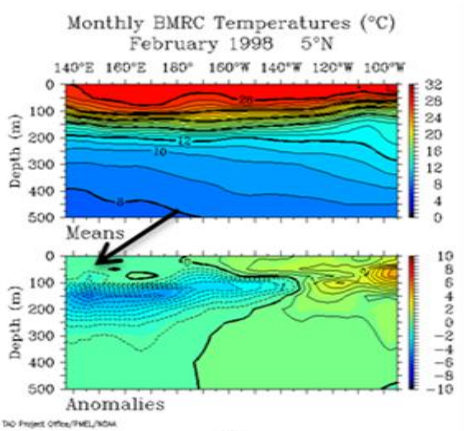

(d)

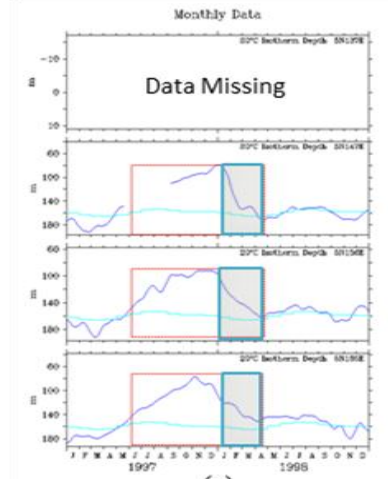

(c)

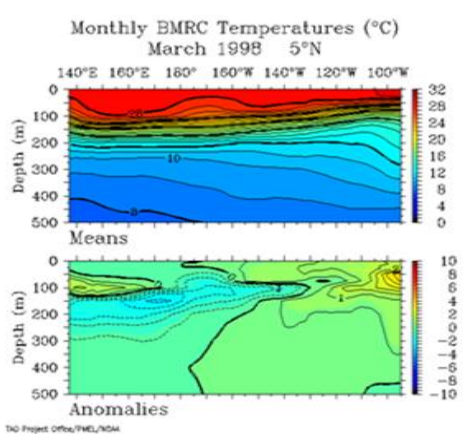

Gambar 5. Diagram Hovmuller plots (Longitude-(xt)) (a) Klorofil-a, SSHA dan SPL, (b) SSHA (Longitude-line) (Januari-Maret)

Figure 5. Hovmuller plots diagram (Longitude-(xt) of (a) Chlorophyll-a, SSHA and SST,(b) SSHA (Longitude-line) (January-March)

Sumber: Hasil analisis 
berhenti atau beristirahat dalam kaitannya dengan medan gelombang Rossby (LaCasce dan Pedlosky, 2004).

Besarnya konstribusi relatif gelombang ekuatorial tersebut terhadap peningkatan produktivitas primer perairan melalui peningkatan klorofil-a permukaan perairan pada perairan sekitar puncak gelombang utama selama musim barat berkisar antara 4-10\% sedangkan di perairan yang dipengaruhi oleh fiture oseanografi lainnya selama musim timur berkisar antara $9-12 \%$.

\subsection{ENSO 1997/1998}

Rambatan gelombang Rossby selama ENSO 1997/1998 kuat di BPWP memberikan efek pengayaan kesuburan melalui peningkatan status perairan dari keadaan oligotropik menjadi mesotropik. Keberadaan gelombang internal ini diindikasikan oleh kenampakan anomali air dingin selama Januari-Februari yang berpusat pada bujur $145^{\circ} \mathrm{E}$ dan $170{ }^{\circ} \mathrm{E}$ pada kedalaman $125-150 \mathrm{~m}$. Intensitas gelombang melemah selama Maret karena kolam hangat mulai bergeser ke timur. Pendangkalan gelombang menyebabkan adveksi vertikal massa air dingin kaya nutrien dengan anomali (-0,5)-(-1) ${ }^{\circ} \mathrm{C}$ pada kedalaman $35-75 \mathrm{~m}$. Fenomena ini juga dijelaskan melalui distribusi kedalaman isoterm $20{ }^{\circ} \mathrm{C}$ indikator kedalaman sentral termoklin di barat Pasifik yang dangkal $(60-100 \mathrm{~m})$ selama musim barat dan lebih dalam(140-160 m) selama musim transisi dan timur (Gambar 3c dan d).

Adveksi vertikal air dingin pada bujur $135-145{ }^{\circ} \mathrm{E}$ mencapai MLD (27-50 m; rerata $40 \mathrm{~m}$ ) di zona eufotik dengan nutrien yang kaya daripinoklin/nitraklin namun kedalaman adveksi maksimum hanya berjarak $5 \mathrm{~m}$ dari jangkauan zona kedalaman optikal SeaWIFS. Sementara pada bujur 147-165 ${ }^{\circ} \mathrm{E}$ kedalaman adveksi tidak menjangkau MLD yang cenderung lebih dalam (26-76 m; rerata $56 \mathrm{~m}$ ) maupun zona kedalaman optikal SeaWIFS. Keadaan ini mengisyaratkan bahwa area perairan berada pada lembah gelombang Rossby dengan pola yang sama dengan data klimatologi bulanan.

Hasil analisis diagram Hovmuller plotsparameter Ocean color, SSHA dan SPL (Gambar 6) juga membuktikan kesesuaian lokasi blooming fitoplankton dengan asupan nutrien baru pada bujur $135-154{ }^{\circ} \mathrm{E}$ dicirikan oleh rendahnya nilai
SSHA ((-16)-(-34) $\mathrm{cm}$ dan (-15)-(-12,5) $\mathrm{cm})$ dan SPL $27{ }^{\circ} \mathrm{C}$ selama Januari-Februari. Puncak blooming terjadi pada Februari dengan konsentrasi klorofil-a $0,06-0,30 \mathrm{mg} / \mathrm{m}^{3}$ (rerata $0,15 \mathrm{mg} / \mathrm{m}^{3}$ ). Selain pengaruh gelombang Rossby, peningkatan kesuburan perairan juga terjadi melalui mekanisme Eddies (April-Mei) dan adveksi cold tangue (JuniJuli) dengan nilai konsentrasi klorofil-a masingmasing berkisar antara $0,03-0,24 \mathrm{mg} / \mathrm{m}^{3}$ (rerata $0,13 \mathrm{mg} / \mathrm{m}^{3}$ ) dan $0,01-0,20 \mathrm{mg} / \mathrm{m}^{3}$ (rerata 0,11 $\left.\mathrm{mg} / \mathrm{m}^{3}\right)$.

Kontribusi relatif gelombang Rossby terhadap peningkatan produktivitas primer permukaan perairan melalui peningkatan konsentrasi klorofil-a selama musim barat berkisar antara 15-38 \% sedangkan Eddies dan cold tangue 3-23 \% (Tabel 1). Besarnya nilai konstribusi gelombang Rossby di BPWP tidak jauh berbeda dengan kontribusinya di beberapa perairan oligotropik dan dikategorikan rendah walaupun Charria et al. (2008) dan Sakamoto et al. (2004) mengusulkan nilai persentase $<25 \%$ untuk kategori rendah. Peningkatan produktivitas primer permukaan perairan BPWP yang rendah seperti yang dijelaskan sebelumnya disebabkan karena taikan lemah sehingga pengangkatan nutrien dan DCM dangkal di atas dasar MLD. Proporsi rendah ini yang dijangkau oleh zona kedalaman optikal satelit sedangkan proporsi terbesar blooming fitoplankton berada di bawah kedua kedalaman tersebut. Fenomena ini merupakan ciri khas sistem perairan oligotropik Pasifik dengan stratifikasi yang kuat dan MLD yang relatif stabil (Mann dan Lazier, 2006).

\subsection{Respons Biogeokimia Perairan}

Respons biogeokimia perairan terhadap gangguan gelombang Rossby direpresentasikan melalui distribusi total klorofil yaitu jumlah semua komponen fitoplankton dan empat group utama fitoplankton terhadap asupan makro dan mikro nutrien baru di perairan (Gambar7). Hasil analisis menunjukkan bahwa total klorofil-a dipengaruhi oleh kehadiran nitrat dan besi terlarut $\left(\mathrm{Fe}_{\mathrm{D}}\right)$ di perairan. Distribusi total klorofil dengan konsentrasi yang tinggi bersesuaian dengan konsentrasi nitrate dan $\mathrm{Fe}_{\mathrm{D}}$ yang meningkat di perairan sekitar puncak gelombang Rossby maupun Eddies. Konsentrasi yang rendah cenderung mengikuti pola distribusi nitrat dengan konsentrasi yang rendah dan $\mathrm{Fe}_{\mathrm{D}}$ yang tinggi di perairan. 

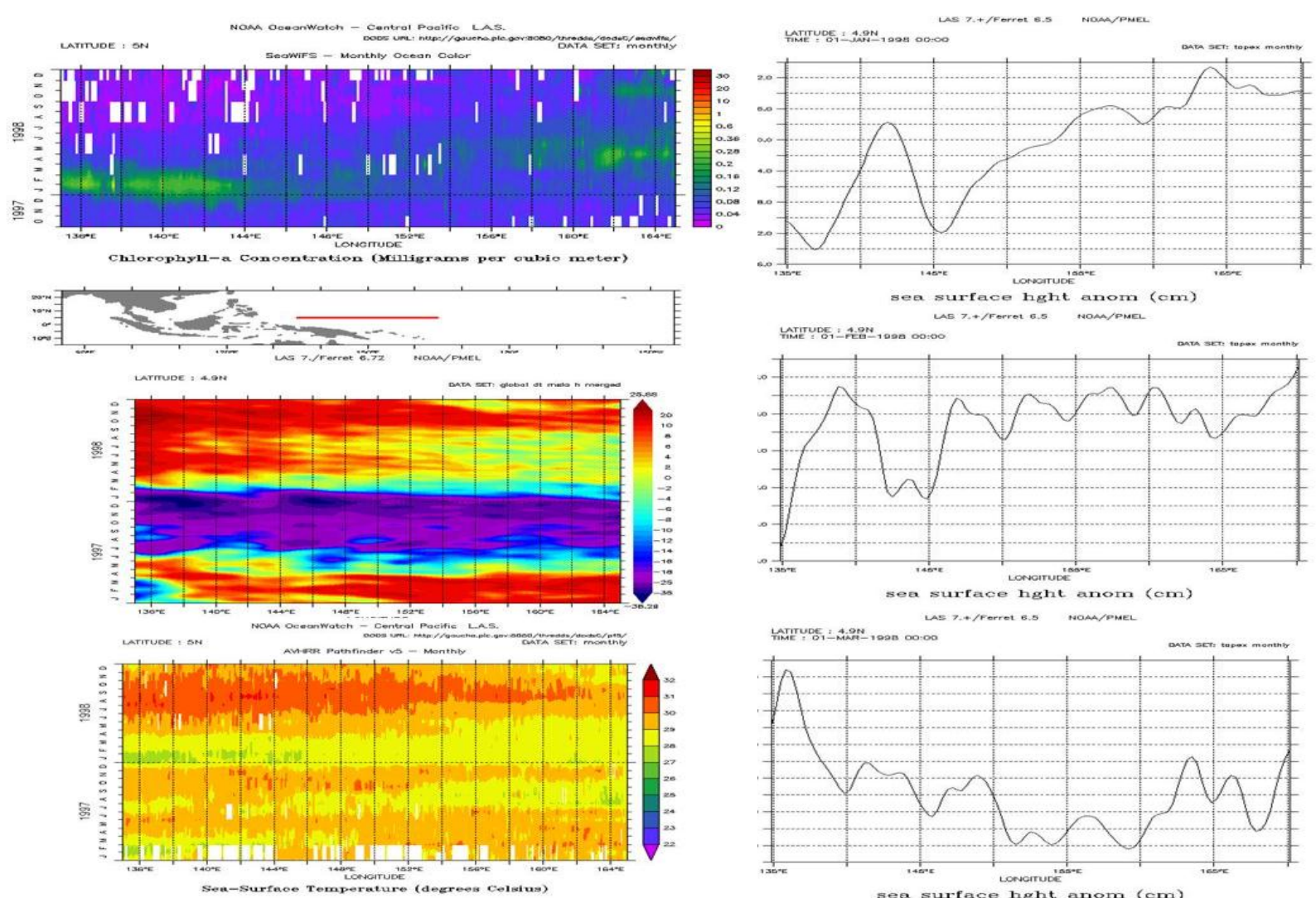

(a)

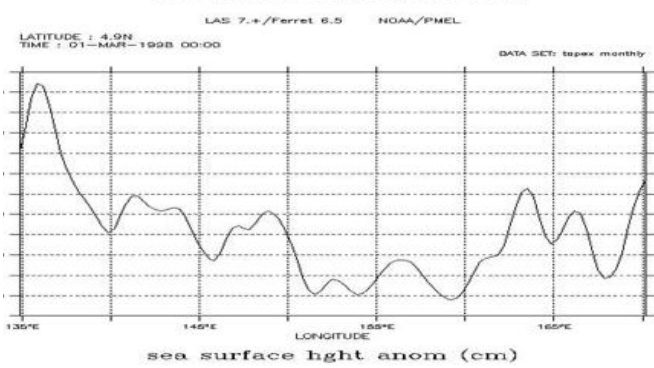

(b)

Gambar 6. Diagram Hovmuller plots (Longitude-(xt)) (a) Klorofil-a, SSHA dan SPL, (b) SSHA (Longitude-line) (Januari-Maret) ENSO 1997/98

Figure 6. Hovmuller plots diagram (Longitud- (xt)) of (a) Chlorophyll-a, SSHA and SST,(b) SSHA (Longitude-line) (January-March) ENSO 1997/98

Sumber: Hasil analisis

Tabel 1. Dampak gelombang Rossby pada produkitivitas primer permukaan perairan oligotropik Table1. Impact of Rossby wave on surface primary productivity oligotrophic waters

\begin{tabular}{|c|c|c|c|c|}
\hline \multirow{2}{*}{ No } & \multirow{2}{*}{ Peneliti } & \multirow{2}{*}{ Lokasi } & \multicolumn{2}{|c|}{ Varians $(\%)$} \\
\hline & & & Rossby & Eddies \\
\hline 1 & Cipollini et al. (2001) & Samudera Hindia & 20 & \\
\hline 2 & Uz et al. (2001) & Utara Pasifik & $2-20$ & $5-20$ \\
\hline 3 & Charria et al. (2008) & Atlantik Utara & 20 & \\
\hline 4 & Sakamoto et al. (2004) & Utara Pasifik Tropis Gyre & 30 & \\
\hline 5 & $\begin{array}{l}\text { Kawamiya dan Oschlies } \\
\text { (2001) }\end{array}$ & Samudera Hindia & 30 & \\
\hline 6 & Pan et al. (2012) & Utara Laut Cina Selatan & $15-37$ & \\
\hline \multirow[t]{3}{*}{7} & Penelitian ini & BPWP & & \\
\hline & & Klimatologi & $4-10$ & $9-12$ \\
\hline & & ENSO 97/98 & $15-38$ & $3-23$ \\
\hline
\end{tabular}


Keadaan ini mengisyaratkan bahwa produktivitas primer dikendalikan oleh ketersediaan nitrat di perairan juga ditentukan oleh $\mathrm{Fe}_{\mathrm{D}}$ sebagai faktor yang membatasi blooming fitoplankton (Christian etal., 2002). $\mathrm{Fe}_{\mathrm{D}}$ merupakan mikro nutrien penting yang mempengaruhi pertumbuhan dan struktur komunitasfitoplankton juga mengontrol biomassa biodiversitas produser primer di perairan (Hassler et al., 2009).

Respons perairan juga diperlihatkan melalui dominasi kelompok fitoplankton Cyanobacteria dan Coccolithopores sebagai kontributor utama fluoresensi fitoplankton di perairan selama ENSO (Gambar 8). Fenomena yang sama juga diperlihatkan oleh Rousseaux dan Gregg (2014) menggunakan NOBM dan menemukan bahwa produktivitas primer perairan Pasifik selama ENSO berkorelasi positif dengan kelompok Cyanobacteria dan Coccolithophores sebaliknya berkorelasi negatif dengan Diatom dan Chlorophytes.

Rendahnya dominasi kelompok Diatom dan Chlorophytes disebabkan oleh laju konsumsi yang tinggi mesozooplankton seperti kopepoda yang melimpah disekitar area taikan (Le Borgne et al., 2011) dan diduga pertumbuhannya oleh $\mathrm{Fe}_{\mathrm{D}}$ yang tinggi di perairan selama ENSO (Christian et al., 2004; Ryan et al., 2006), walaupun keduanya memiliki laju pertumbuhan yang lebih cepat dari group fitoplankton lainnya.

Fenomena menarik dari hasil studi ini adalah korelasi hasil analisis NOBM dengan hasil penelitian yang mengacu pada Anderson (2013), Meranon dan Varela (2005) dan Perez et al. (2006) bahwa sebagian besar produktivitas primer dan grazing di perairan Pasifik didominasi oleh Cyanobacteria (Genus Prochlorococcus) anggota microbial loop. Kelimpahannya yang tinggi mendekati dasar zona eufotik yang juga bersesuaian dengan kedalaman nitraklin, DCM (Brynt, 2003) dan zona kelimpahan tinggi zooplankton (Mann dan Lazier, 2006). Hasil eksperimen tagging Madidihang di perairan sekitar Hawaii menunjukkan bahwa spesies tuna tersebut menyelam lebih dalam $(50-100 \mathrm{~m})$ pada malam hari untuk makan dalam DCM. Kehadirannya dalam DCM berasosiasi dengan makanan tuna (prey) seperti myctophidae, euphosiid dan udang yang mengkonsumsi sebagian besar Prochlorococcus dan teridentifikasi dalam isi lambung Madidihang dewasa (Anderson, 2013). Hal ini mengindikasikan bahwa: (1) ada korelasi antara kelimpahan kelompok Cyanobacteria dengan kehadiran prey dan tuna di sekitar puncak gelombang Rossby dan dalam DCM yang ditenggelamkan di bagian lembah gelombang, dan (2) kelimpahan prey dalam DCM merupakan faktor kunci eksistensi perairan oligotropik BPWP sebagai daerah penangkapan utama tuna.

\subsection{Kelimpahan dan Laju Tangkapan (CPUE)}

Dampak gelombang Rossby terhadap perikanan tuna tercermin melalui signifikansi distribusi daerah penangkapan Cakalang (Katsuwonus pelamis), Madidihang (Thunnus albacares) dan Tuna Mata Besar (Thunnus obesus) di perairan sekitar cross section gelombang Rossby. Hasil analisis menunjukkan bahwa 85,71 \% daerah penangkapan ketiga spesis tuna cenderung mendominasi perairan sekitar puncak gelombang (zonal $5{ }^{\circ} \mathrm{N}$ : bujur $135-145^{\circ} \mathrm{E}$ ) sedangkan sisanya $14,28 \%$ berada di lembah gelombang. Penangkapan pada puncak gelombang bersesuaian dengan konsentrasi klorofil-a yang tinggi $(0,06-0,3$ $\mathrm{mg} / \mathrm{m}^{3}$; rerata $\left.0,15 \mathrm{mg} / \mathrm{m}^{3}\right)$, SSHA yang rendah $((-$ 16)-(-12,5) cm), SPL $27{ }^{\circ} \mathrm{C}$ lebih rendah dari keadaan normal dan berasosiasi dengan kelimpahan yang tinggi dari kelompok Cyanobacteria di permukaan perairan maupun dalam DCM yang ditenggelamkan. Penangkapan tuna di lembah gelombang berhubungan dengan kelimpahan Cyanobacteria yang tinggi dalam DCM.

Hasil analisis produktivitas penangkapan tuna yang diukur menggunakan indikator kelimpahan dan laju tangkapan (CPUE) menunjukkan bahwa produktivitas penangkapan tuna meningkat selama musim barat (Januari-Maret) jika dibandingkan dengan musim timur yang tidak disertai dengan kehadiran gelombang Rossby pada cross section (Gambar 9). Cakalang memiliki kelimpahan dan CPUE yang paling tinggi diantara dua spesies tuna lainnya yaitu 3.863 ton dan 7 ton/hari dengan puncak penangkapan terjadi pada Januari (7.779 ton; 11 ton/hari). Pola yang sama juga diperlihatkan oleh Madidihang dengan kelimpahan dan CPUE 372 ton dan 1.42 ton/hari (855 ton; 1.41 ton/hari). Sementara itu, Tuna Mata Besar yang hidup dalam lapisan termoklin memiliki kelimpahan dan CPUE yang lebih rendah dari kedua spesis tuna sebelumnya yaitu 134 ton; 0,23 
(a)

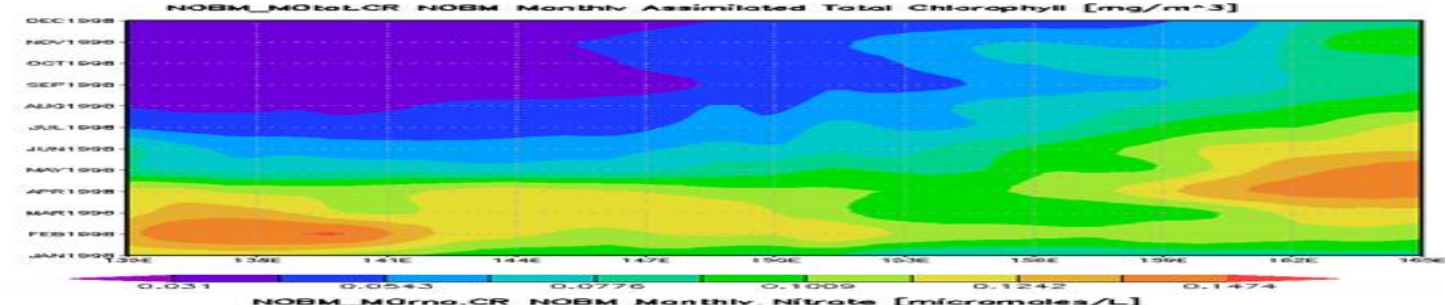

(b)

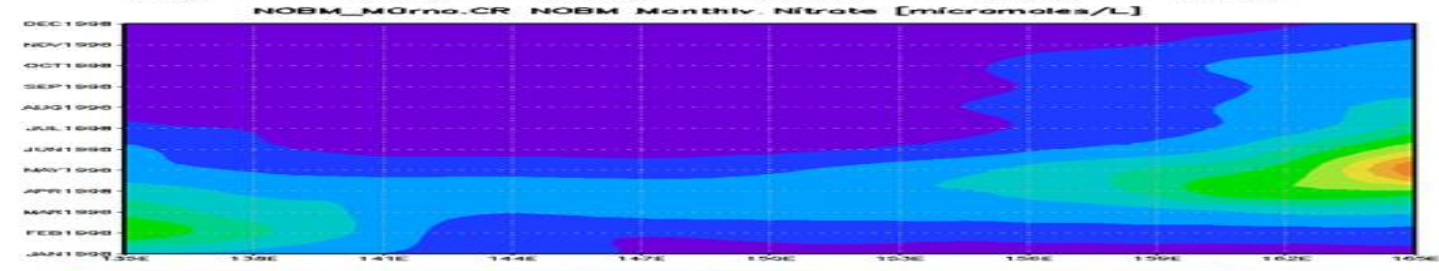

(c)

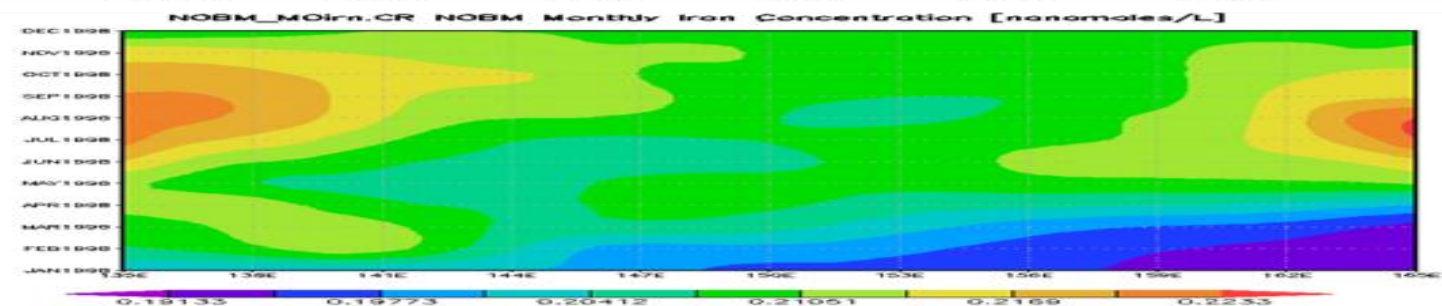

Gambar 7. Diagram Hovmuller plots (Longitude-(xt)) (a) Total klorofil, (b) Nitrat,dan (c) $\mathrm{Fe}_{\mathrm{D}}$ ) Figure 7. Hovmuller plots diagram (Longitude-(xt)) of (a) Total chlorophyll, (b) Nitrate and (c) $\left.F e_{D}\right)$ Sumber: Hasil analisis
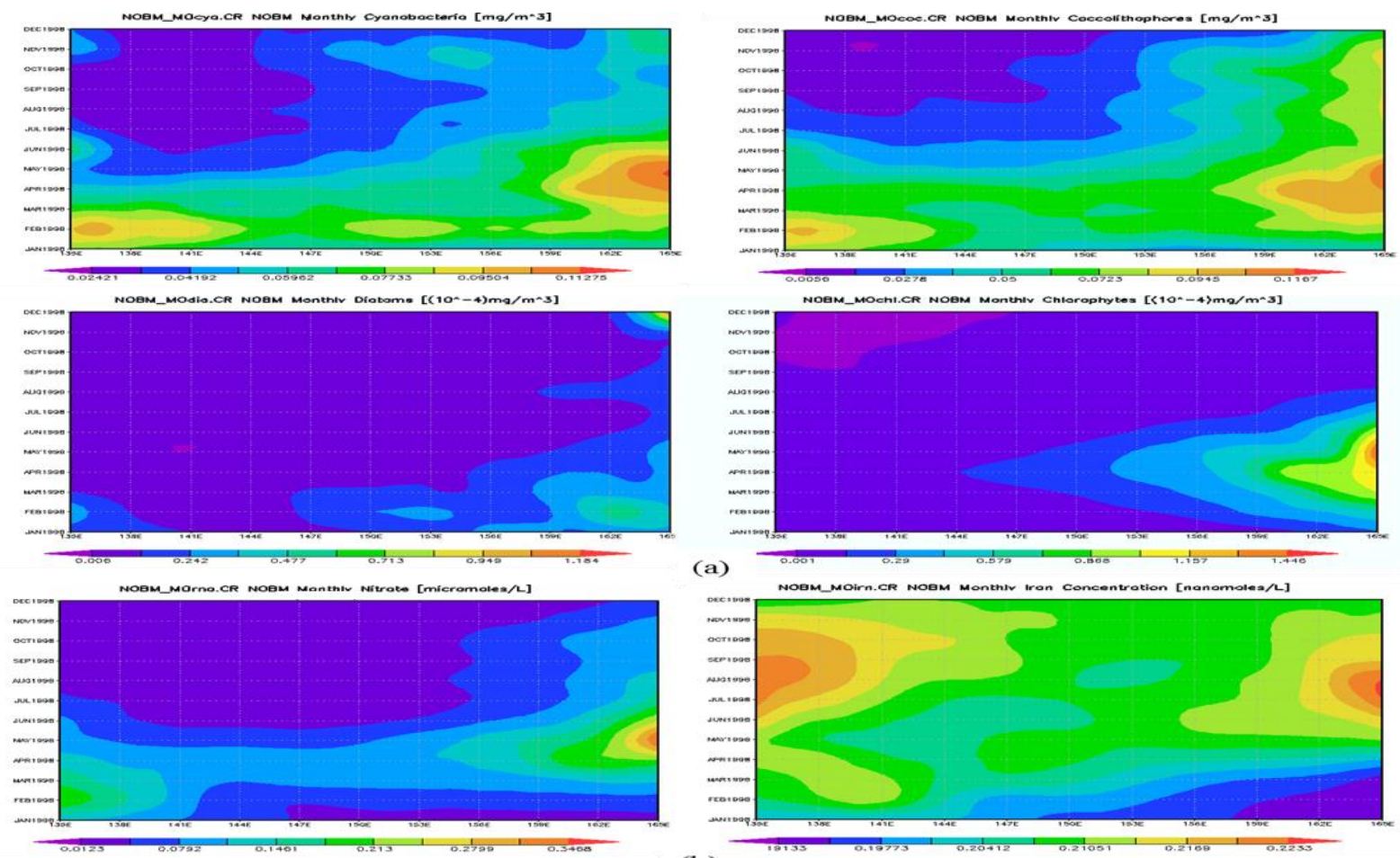

(a)

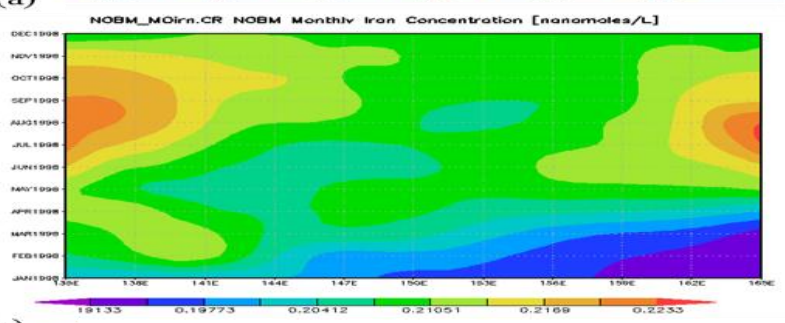

(b)

Gambar 8. Diagram Hovmuller plots (Longitude-(xt)) respons (a) kelompok fitoplankton, (b) Nitrat dan $\mathrm{Fe}_{\mathrm{D}}$ ) Figure 8. Hovmuller plots diagram (Longitude-(xt)) of (a) phytoplankton group respons, $(b)$ Nitrate and $F e_{D}$ ) Sumber: Hasil analisis 
ton/hari dengan puncak penangkapan terjadi pada Maret(143 ton ;0,35 ton/hari).
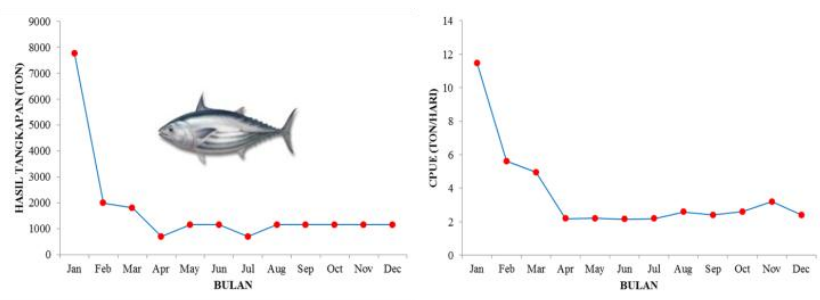

(a) Cakalang (Katsuwonus pelamis)
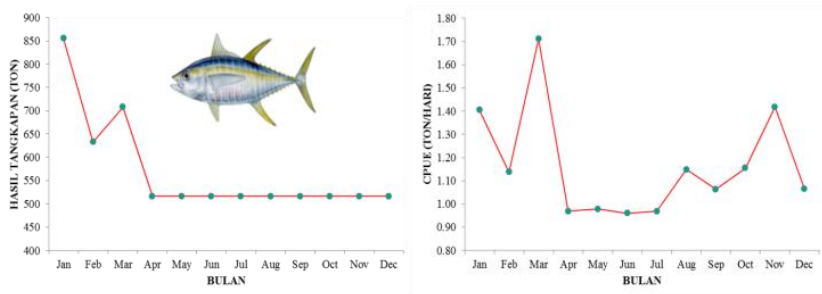

(b) Madidihang (Thunnus albacares)

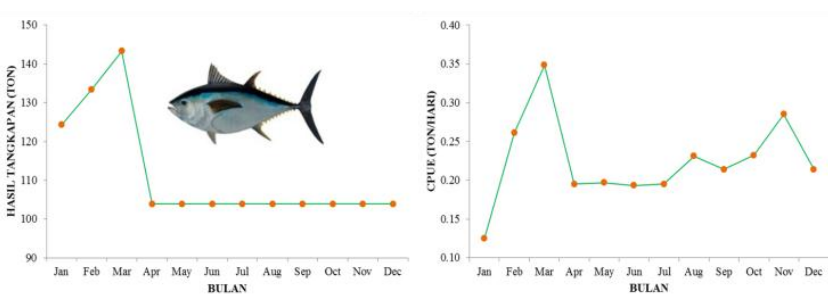

(c) Tuna Mata Besar (Thunnus obesus)

Gambar 9. Kelimpahan dan laju tangkapan (CPUE)

(a) Cakalang, (b) Madidihang dan (c) Tuna Mata Besar

di sekitar cross section

Figure 9. Abudance and catch rate (CPUE) of (a)

Skipjack tuna, (b) Yellowfin tuna and (c) Bigeye tuna in surrounding of cross section

Sumber: Hasil analisis

Hasil analisis data penangkapan armada tuna Purse seine Jepang yang lebih representatif mewakili kawasan perairan BPWP pada tahun yang sama menunjukkan pola yang sama, dimana kelimpahan dan laju tangkapan relatif ketiga spesies tuna tersebut cenderung meningkat selama musim barat. Hasil tangkapan didominasi oleh Cakalang sebesar 80,91\% diikuti oleh Madidihang dan Tuna Mata Besar sebesar 18,34 \% dan 0,73\%. Kelimpahan dan CPUE maksimum Cakalang dan Madidihang terjadi selama Februari masing-masing sebesar 17.000 ton $(6,7$ ton/hari) dan 400 ton $(1,5$ ton/hari). Berbeda dengan kedua spesies tuna sebelumnya, kelimpahan maksimum Tuna Mata Besar meningkat selama Januari (499 ton), namun dengan CPUE maksimum (0,24 ton/hari) selama Maret (Gambar 10). Indikasi yang sama juga diperlihatkan melalui peningkatan hasil tangkapan tuna di beberapa negara kepulauan barat Pasifik seperti Solomon, Palau, Indonesia, Filipina, dan Papua New Guinea selama akhir dari periode ENSO pada Januari-Maret (Lehodey, 2000). Dari hasil kajian ini dapat dijelaskan bahwa gelombang Rossby bertanggung jawab terhadap meningkatkan kesuburan perairan dan pola musim penangkapan tuna di BPWP.
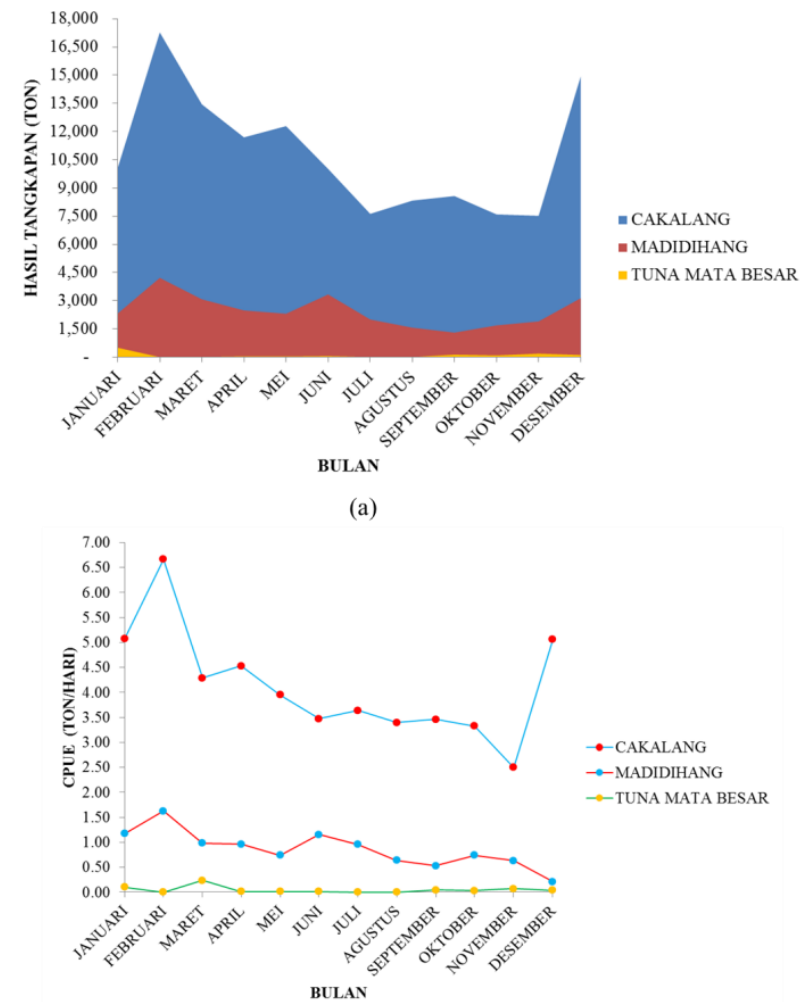

(b)

Gambar 10. Kelimpahan dan laju tangkapan (CPUE)

(a) Cakalang, (b) Madidihang dan (c) Tuna Mata Besar di BPWP

Figure 10. Abudance and catch rate (CPUE) (a) Skipjack tuna, (b) Yellowfin tuna and (c) Bigeye tuna in WPWP

Sumber: Hasil analisis

\section{KESIMPULAN DAN SARAN}

Gelombang Rossby tampak meningkatkan kesuburan perairan BPWP melalui peningkatan produktivitas primer perairan selama musim barat akhir dari episode ENSO (Januari-Maret). Peningkatan produktivitas primer perairan ditunjukkan melalui peningkatan klorofil-a dan 
total klorofil dari keadaan oligotropik menjadi mesotropik terutama pada perairan oseanik di sekitar puncak gelombang. Namun demikian, peningkatan tersebut relatif rendah jika dibandingkan dengan kedalaman di bawah MLD dan zona kedalaman optikal SeaWIFS. Produksi primer dan grazing di permukaan perairan dan dalam DCM didominasi oleh kelompok fitoplankton Cyanobacteria dan Coccolithophores sekaligus sebagai penyumbang terbesar fluoresensi fitoplankton dan dasar dari rantai makanan tuna dan ikan pelagis besar lainnya di perairan. Kelimpahan group Diatom dan Chlorophytes cenderung lebih rendah karena laju konsumsi yang tinggi kedua genus tersebut oleh kopepoda yang melimpah diperairan dengan asupan nutrien yang tinggi. Secara signifikan gelombang internal tersebut mempengaruhi pola distribusi daerah penangkapan, kelimpahan dan laju tangkapan dan musim penangkapan tuna di perairan BPWP.

Disarankan agar dilakukan studi lanjutan pengaruh coastal upwelling di utara kontinen Papua di bawah pengaruh anomali angin barat karena diduga fenomena tersebut turut berperan penting meningkatkan kesuburan perairan dan menunjang kehadiran tuna di perairan BPWP.

\section{DAFTAR PUSTAKA}

Anderson, E. (2013). The Deep Chlorophyll Maximum in Fiji Waters. Pacific Science Inter- congress.

Block, B. A., \& Stevens, E. D. (2001). Tuna: Pshyology, Ecology and Evolution. Academic Press. Elsevier

Bryant, D. A. (2003). The beauty of small things revealed. Proceeding of the National Academic of Science, 100 (17), 9647-9649.

Charria, G., Dadou, I., Ciphollini, P., Drevillon, M., \& Garcon, V. (2008). Influence of Rossby waves on primary production from a coupled physicalbiogeochemical model in the North Atlantic Ocean. Ocean Sci., (4), 199-213.

Chelton, D. B., Schlax, M. G., Lyman, J. M., \& Jhonson, G. C. (2003). Equatorially trapped Rossby waves in the presence of meredionally sheared baroclinic flow in the Pacific Ocean. Progress in Oceanography, (56), 323-380.

Christian, J. R., Verschell, M. A., Murtugudde, R., Busalacchi, A. J., \& McClain C. R. (2002). Biogeochemical modelling of the tropical Pacific Ocean. I. Seasonal and interannual variability. Deep-Sea Research II, (49), 509-543.
Christian, J. R., Murtugudde R., Ballabrera-Poy, J. \& McClain, C. R. (2004). A ribbon of dark water: phytoplankton blooms in the meanders of the Pasific north equatorial countercurrent. DeepSea Research II, (51), 209-228.

Cipollini, P., Cromwell, D., Challenor, P. G., \& Raffaglio, S. (2001). Rossby wave detected in global ocean colour data. Geophysical Research Letters, (28), 323-326.

Ganachaud, A. S., Gupta, A. S., Orr, J. C., Wijffels, S. E., Ridgway, K. R., Hemer, M. A., et al. (2011). Observed and Expected Changes to the Tropical Pacific ocean. Secretariat of the Pacific Community, 101-189.

Hassler, C., Petrou, K., Clementson, L., Blackburn, S., \& Butler, E. (2009). Iron limitation for Southern Ocean Diatom (Chaetoceros sp.) and Haptophyte (Phaeocystis sp.): impact on physiology and iron bioavailability, in preparation.

Gregg, W. W., \& Casey, N. W. (2007). Modeling coccolithophores in the global oceans. Deep-Sea Research II, (54), 447-477.

Kawamiya, M., \& Oschlies, A. (2001). Formation of a basin-scale surface chlorophyll pattern by Rossby waves. Geophysical Research Letters, 28(21), 4139-4142.

Killworth, P. D., Cipollini, P., Uz, B. M., \& Blundell, J. R. (2007). Physical and biological mechanisms for planetary waves observed in sea-surface chlorophyll. J. Geophys. Res, 109(C7), C07002.

Krauss, W. (1967). Interaction Between Surface and Internal Waves in Sahllow Water. U.S. Navy. Electronic Laboratory. Oceanograpy Research Tower site.

Krosmeyer, K. E., \& Dewar, H. (2001). Tuna Metabolism and Energetics. In B.A. Block \& E.D. Stevens (Eds.), Tuna: Physiology, Ecology and Evolution: Academic Press, San Diego.

La Casce, J. H. \& Pedlosky, J. (2004). The instability of rossby basin modes and the oceanic eddy field. Journal of Physical Oceanography, 34, 20272041.

Le Borgne, R., Allain, R. T. V., Griffiths, S. P., Matear, R. J., McKinnon, A. D., \& Richardson, A. J. (2011). Vulnerability of Open Ocean Food Webs in The Tropical Pacific to Climate Change. Secretariat of the Pacific Community, 189-249.

Lehodey, P. (2000). Impact of El Nino Souther Oscillation on Tuna population and Fisheries in the Tropical Pacific Ocean. Oceanic Pacific Programme. Secretariat of Pacific Community. New Calidonia.

Lehodey, P., Hampton, J., Brill, R. W., Simon, N., Senina, I., Calmettes, B., et al. (2011). Vulnerability of Oceanic Fisheries in the 
Tropical Pacific to Climate Change. Secretariat of the Pacific Community, 435-485.

Lin I, Liu, W. T., Wu, C. C., Wong, G. T. F., Hu, C., Chen, Z., et al. (2003). New evidence for enhanced ocean primary productivity triggered by tropical cyclone. Geophys Res Lett, 30(13), 1718.

Mackey, D. J., Blanchot, J., Higgins, H. W., \& Neveux J. (2002). Phytoplankton abudances and community structure in the equatorial Pacific. Deep-Sea Research II, (49), 2561-2582.

Mann, K. H., \& Lazier J. R. (2006). Dynamics of Marine Ecosystems: Biological-physical Interactions in the Oceans. Blackwell Publishing.

Maranon, E., \& Varela, M. (2005). Basin-scale patterns of phytoplankton abundance, composition and production in the Atlantic Ocean. Report of Atlantic Meridional Transect cruise AMT-2, Plymouth Marine Laboratory.

McGillicuddy, D. J., \& Robinson, A. R. (1998). Influence of mesoscale eddies on new production in the Sargaso Sea. Nature 394, (6690), 263-266.

McPhaden, M. J. (1999). Genesis and evolution of the 1997-1998 El Nino. Science. doi:10.1126/science.283.5404.950.

Mysak, L. A., Hsieh, W. M., \& Parsons, T. R. (1982). On the relationship between interannual baroclinic waves and fish populations in the Northeast Pacific. Biol Oceanogr, (2), 63-103.

Pan, X., Wong, G. T. F., Fuh-Kwo Siah, Tung-Yuan Ho. (2011). Enhancement of biologycal productivity by internal waves : observations in the summertime in the northern south China Sea. Journal Oceanography. Doi : 10.10007/s10872012-0107-y.

Pérez, V., Fernándeza, E., Marañona, E., Moránb, X. A. G., \& Zubkov, M. V. (2006). Vertical distribution of phytoplankton biomass, production and growth in the Atlantic subtropical gyres. Deep-Sea Research I, 53, 1616-1634.

Pre Spare, \& Venema, S. C. (1999). Introduction to Tropical Fish Stock Assessment. FAO.

Radenac, M. H., \& Rodier, M. (1996). Nitrate and chlorophyll distribution in relation to thermohaline and current structure in the Western Tropical Pacific during 1985/89. Deep Sea Research II, 43, 725-752.

Rousseaux, C. S., \& Gregg, W. W. (2014). Interannual variation in phytoplankton primary at a global scale. Remote Sensing, Open Acces, 6, 1-19. doi:10.3390/rs6010001.

Ryan, J. P., Ueki, I., Chao, Y., Zhang, H., Polito, P. S., \& Chavez, F. P. (2006). Western Pacific modulation of large phytoplankton blooms in the central and eastern equatorial Pacific. Journal of Geophysical Research, Vol. 111, doi:10.1029/2005JG000084.
Sakamoto, C. M., Karl, D. M., Jannasch, H. W., Bidigare, R. R., Letelier, R. M., Walz, P. M., et al. (2004). Influence of Rossby waves on nutrien dynamics and the plankton community structure in the North Pacific subtropical gyre. Journal of Geophysical Research, 109, 1-12.

Siegel, D. (2001). The Rossby rototiller. Nature, 409, 576-577.

Tomczak, M., \& Godfrey, J. S. (2001). Regional Oceanography: An Introduction. This edition published online (C) M.Tomczack and J. S. Godfrey.

Uz, B. M., Yoder, J. A., \& Osychny, V. (2001). Pumping of nutrients to ocean surface waters by the action of propagating planetary waves. Nature, 409, 597-600.

Villareal, T. A., Joseph, L., Brzezinski, M. A., Shipe, R.F., Lipschultz, F., \& Altabet, M. A. (1999). Biological and chemical characteristics of the giant diatom ethmodiscus (bacillariophyceae) in the central north Pacific gyre. J. Phycol, 35, 896902.

White, W. B., Gloersen, K. A., Marsac, F., \& Tourre,Y. M. (2004). Influence of coupled rossby wave on primary productivity and tuna abudance in the Indian Ocean. Journal of Oceanography, 60, 531-541.

Yu, X., \& McPhaden, M. J. (1999). Seasonal variability in the equatorial Pacific. Journal Phys. Oceanography, 29, 925-947. 